\title{
Treatment of Liver Cancer
}

\author{
Chun-Yu Liu ${ }^{1,2,3}$, Kuen-Feng Chen ${ }^{4,5}$, and Pei-Jer Chen ${ }^{4,5,6}$ \\ ${ }^{1}$ Department of Medicine, Division of Hematology and Oncology, Taipei Veterans General Hospital, \\ Taipei 112, Taiwan \\ ${ }^{2}$ School of Medicine, National Yang-Ming University, Taipei 112, Taiwan \\ ${ }^{3}$ Institute of Biopharmaceutical Sciences, National Yang-Ming University, Taipei 112, Taiwan \\ ${ }^{4}$ Department of Medical Research, National Taiwan University College of Medicine, Taipei 112, Taiwan \\ ${ }^{5}$ National Center of Excellence for Clinical Trial and Research, National Taiwan University College \\ of Medicine, Taipei 112, Taiwan \\ ${ }^{6}$ Graduate Institute of Molecular Medicine, National Taiwan University Hospital and National Taiwan \\ University College of Medicine, Taipei 112, Taiwan \\ Correspondence: peijerchen@ntu.edu.tw
}

Primary liver cancer, mostly hepatocellular carcinoma, remains a difficult-to-treat cancer. Incidence of liver cancer varies geographically and parallels with the geographic prevalence of viral hepatitis. A number of staging systems have been developed, reflecting the heterogeneity of primary liver cancer, regional preferences, and regional variations in resectability or transplant eligibility. Multimodality treatments are available for this heterogeneous malignancy, and there are variations in the management recommendations for liver cancers across specialties and geographic regions. Novel treatment strategies have merged with the advance of new treatment modalities. This work focuses on reviewing the incidence, staging, and treatment of liver cancer.

Iver cancer is a cancer that originates in the Lliver, and is an aggressive tumor that frequently occurs in the setting of chronic liver disease and cirrhosis. Primary liver cancer, or hepatocellular carcinoma (HCC), is the fifth most common cancer in males and the seventh most common cancer in females, and is the third leading cause of cancer-related death worldwide (Ferlay et al. 2010; Jemal et al. 2011). The incidence of liver cancer is increasing in the United States, reaching an annual incidence of 4.5 per 100,000 in 2005 (Altekruse et al. 2009). Despite advances in its treatment, liver cancer remains one of the most difficult cancers to treat. For patients with early HCC, surgery, local destructive therapies, and liver transplantation provide curative potential. However, recurrence of HCC remains a major problem after curative treatment, reaching an incidence of more than $70 \%$ at $5 \mathrm{yr}$ (Llovet et al. 2005). Even in patients with early, small HCC $(<3 \mathrm{~cm})$ receiving surgery, the 5 -yr survival rate is not satisfactory $(47 \%$ to $53 \%$ ) (Poon et al. 2002; Altekruse et al. 2012; Fong and Tanabe 2014). Typically, HCC

Editors: Christoph Seeger and Stephen Locarnin

Additional Perspectives on Hepatitis B and Delta Viruses available at www.perspectivesinmedicine.org

Copyright (C) 2015 Cold Spring Harbor Laboratory Press; all rights reserved; doi: 10.1101/cshperspect.a021535

Cite this article as Cold Spring Harb Perspect Med 2015;5:a021535 
C.-Y. Liu et al.

is often diagnosed at an advanced stage, and many patients with advanced stage are not eligible for the curative therapies. Moreover, traditional systemic chemotherapy shows low efficacy and little survival benefits (Verslype et al. 2009). The approval of a multikinase inhibitor, sorafenib, has shown some survival benefit in patients with advanced HCC and preserved liver function, highlighting a promising molecular targeted strategy for advanced HCC (Llovet et al. 2008).

Treatment of liver cancer is now multidisciplinary, and multimodel treatment options are chosen generally on an individualized basis according to the complex interplay of tumor stage and the extent of underlying liver disease, as well as the patient's overall general health. There are variations in the recommendations for the management of liver cancers across the specialties and geographic regions. Heterogeneity in management of liver cancer exists across the various guidelines from the United States (National Comprehensive Cancer Network [NCCN]), Europe (European Association for the Study of the Liver-European Organization for Research and Treatment of Cancer [EASLEORTC]), and Asia (consensus statement from the Asian Oncology Summit 2009 [AOS]) (Poon et al. 2009; Fong and Tanabe 2014). This work focuses on reviewing the incidence, monitoring, and treatment of liver cancer.

\section{INCIDENCE OF LIVER CANCER}

Globally, the incidence of liver cancer is more than twice as high in males as in females. The highest liver cancer rates are found in East and Southeast Asia and in Middle and Western Africa, whereas rates are low in South-Central and Western Asia, as well as Northern and Eastern Europe (Jemal et al. 2011). These regional differences in incidence of liver cancer reflect regional variations in exposure to hepatitis viruses and environmental pathogens. In developing countries, hepatitis B virus (HBV) infection accounts for about $60 \%$ of the total liver cancer in developing countries, whereas hepatitis $\mathrm{C}$ virus (HCV) infection accounts for about $33 \%$ of total liver cancer (Parkin 2006). The incidence of liver cancer is increasing in the United States and Central Europe, possibly because of the obesity epidemic and the increase in HCV infection through continued transmission by injecting drug users (Jemal et al. 2011). In the United States and several other low-risk Western countries, alcohol-related cirrhosis and possibly nonalcoholic fatty liver disease, associated with obesity, are thought to account for the majority of liver cancer (Jemal et al. 2010). In contrast, liver cancer incidence rates have decreased in some historically high-risk areas, possibly because of the HBV vaccine (Bosetti et al. 2008; Jemal et al. 2010). A universal infant hepatitis vaccination program initiated in 1984 in Taiwan has significantly reduced liver cancer incidence rates in children aged 6-19 yr, showing an ageand sex-adjusted relative risk of 0.31 for persons vaccinated at birth (Chang et al. 2009b).

\section{STAGING OF LIVER CANCER}

There have been a number of staging systems for the prognosis of HCC, including the commonly used tumor-node metastasis (TNM), Okuda, and Barcelona Clinic Liver Cancer (BCLC) systems, as well as the Cancer of the Liver Italian Program (CLIP) score (Okuda et al. 1985; Chevret et al. 1999; Llovet et al. 1999; Kudo et al. 2003, 2004; Pons et al. 2005; Ikai et al. 2006; Edge et al. 2010). The multiplicity of these staging systems reflects the heterogeneity of HCC, regional preferences, and regional variations in resectability or transplant eligibility. Nevertheless, these systems do incorporate important determinants of survival including the size of the tumor, the severity of underlying liver disease, tumor extension into adjacent structures, and tumor metastases. Apart from the American Joint Committee on Cancer (AJCC) TNM system, newer staging systems such as CLIP, BCLC, Groupe d'Etude du Treatment du Carcinome H'epatocellulaire (GRETCH), Chinese University Prognostic System (CUPI), and Japan Integrated Staging (JIS) systems have included patient-dependent variables such as the severity of cirrhosis and a tumor-dependent variable regarding the extent of the HCC (CLIP 1998, 2000; Chev- 
ret et al. 1999; Llovet et al. 1999; Leung et al. 2002; Kudo et al. 2004).

\section{TNM Staging}

The AJCC TNM staging system for HCC, revised in 2010, identifies the most important prognostic factors: the number of tumors and the presence and extent of vascular invasion within the tumor (Edge et al. 2010). Notably, the AJCC TNM staging system neither uses the presence of liver cirrhosis nor incorporates tumor grade to assign the final tumor stage, but instead adopted the fibrosis score of the underlying liver as a clinically significant prognostic factor. The 5-yr survival rates according to the TNM stage I, II, and III are 55\%, 37\%, and $16 \%$, respectively. The prognostic value of the AJCC TNM staging system has been validated prospectively in patients undergoing surgical resection or liver transplantation for HCC (Vauthey et al. 2007; Lu et al. 2008). However, patients with unresectable HCC cannot be accurately staged by this system, thereby limiting the use of AJCC TNM staging in this patient population.

\section{Okuda System}

The prognostic scoring system proposed by Okuda and colleagues includes tumor size and severity of cirrhosis, measured by the amount of ascites, serum albumin, and bilirubin levels (Okuda et al. 1985). Survival for untreated patients with Okuda stages I, II, and III was 8.3, 2.0, and 0.7 mo, respectively. The Okuda system does not include pathologic characteristics, such as vascular invasion or the presence or absence of nodal metastases, and patients staged according to this system mostly had unresectable HCC, thereby limiting its use as a clinical scoring system.

\section{CLIP Score}

The CLIP score, ranging from 0 to 6 , combines an index of the severity of liver cirrhosis (ChildPugh stage), tumor morphology and extension, serum $\alpha$-fetoprotein (AFP) levels, and portal vein thrombosis to determine prognosis of patients with liver cancer. The CLIP scoring system has been shown to be useful in stratifying patients with advanced HCC (CLIP 2000; Ueno et al. 2001; Huitzil-Melendez et al. 2010). Cho et al. (2008) showed that the CLIP system (compared with six other staging systems, including Child-Pugh, Okuda, BCLC, CLIP, modified CLIP, JIS, and modified JIS scores), provided the best prognostic stratification in a cohort of 131 unresectable/untransplantable patients undergoing transarterial chemoembolization (TACE). More recently, Huitzil-Melendez et al. (2010) also compared the same seven staging systems as Guglielmi et al. (2008) in a cohort of 187 patients with advanced HCC, and showed that the CUPI and CLIP staging systems ranked the highest in predicting survival in patients with advanced HCC.

\section{BCLC Staging System}

The BCLC staging system identifies clinical stages based on the extent of the primary tumor, vascular invasion, and extrahepatic spread by tumor, individual persons' performance status, and baseline liver function (Child-Pugh stage). This system is based more on clinical practice, and allows an appropriate treatment strategy to be applied to each BCLC stage. The very early (stage 0 ) and early stage (stage A) patients present with tumors that are amendable to potentially curative treatment (surgical resection, liver transplantation, or local ablation); intermediate (stage B) patients have multinodular tumors, which are treated by TACE; in contrast, advanced (stage C) patients have tumors with vascular invasion and/or extrahepatic spread and, therefore, it is recommended that they be treated with sorafenib; finally, patients with stage D tumors have the worst performance status, have cirrhosis, and are treated with the best supportive care. Marrero and colleagues (2005) compared seven staging systems (Okuda, TNM, BCLC, CLIP, GRETCH, CUPI, and JIS) and concluded that the BCLC system provided the best prognostic stratification for a cohort of 244 patients presenting with cirrhosis and HCC (Marrero et al. 2005). Similarly, Gu- 
glielmi et al. (2008) also compared the same seven staging systems and confirmed that the BCLC system was superior to the other six systems when evaluated in a cohort of 112 HCC patients who underwent radiofrequency ablation (RFA). Although the BCLC system has been prospectively validated in an Italian cohort of 195 HCC patients treated mainly with radical therapies (Cillo et al. 2006), there have been controversies surrounding the BCLC system, particularly in its application in surgical treatment for HCC patients (Ishizawa et al. 2008; Torzilli et al. 2008; Vitale et al. 2011). Nevertheless, the BCLC system has provided an algorithmic approach for the treatment of liver cancer, and new treatments can be tested in different stratification groups.

\section{Choice of Staging System}

There is no consensus as to which staging system is the best, and studies comparing different staging systems have shown variable prognostic values of these systems in various patient populations (Kudo et al. 2004; Marrero et al. 2005; Cho et al. 2008; Guglielmi et al. 2008; Lu et al. 2008; Huitzil-Melendez et al. 2010). Because there is great heterogeneity in geographic variations of treatment approaches and severity of underlying liver functions, it is clear that no universal staging system will accurately accommodate all patient and tumor variables. It is likely that a certain scoring system would be optimal for a certain patient population. For example, pathologic staging systems such as the AJCC TNM staging system may be superior to clinical systems in prognosis classification for patients with surgical resection, whereas clinical systems, such as BCLC and CLIP systems, may have more prognostic value for patients with advanced HCC and cirrhosis who are not candidates for surgery (Vauthey et al. 2010). Further studies are needed to improve the current staging systems and to provide sufficient flexibility for clinical application of these systems across a broader range of patient populations. For convenience, this chapter uses the BCLC system to discuss treatment for liver cancer in the present context.

\section{TREATMENT FOR ADVANCED DISEASE}

\author{
Systemic Therapy
}

\section{Standard Frontline Therapy}

Sorafenib, a multiple kinase inhibitor that represses the activity of Raf- 1 and other tyrosine kinases, such as vascular endothelial growth factor receptor 2 (VEGFR-2), VEGFR-3, Fmslike tyrosine kinase 3 (FLT3), platelet-derived growth factor receptor (PDGFR), and fibroblast growth factor receptor 1 (FGFR-1) (Liu et al. 2006), is the first targeted therapy approved for the treatment of advanced HCC in patients with relatively preserved liver function. The Sorafenib Hepatocellular Carcinoma Assessment Randomized Protocol (SHARP) trial was a landmark multicenter phase III randomized study, which enrolled 602 patients with unresectable HCC or with HCC who failed on locoregional therapy. The results of the study showed a significant improvement in overall survival (OS) in these advanced HCC patients receiving sorafenib compared with placebo (10.7 mo vs. 7.9 mo; hazard ratio, 0.69; $p<0.001$ ) (Llovet et al. 2008). Notably most ( $>90 \%$ ) patients enrolled in the SHARP trial had preserved liver function (Child-Pugh Class A) and good performance status (Eastern Cooperative Oncology Group performance status of 0 or 1 ). The subsequent Asia-Pacific trial by Cheng et al. (2009) also revealed survival benefits of sorafenib ( 6.5 mo vs. $4.2 \mathrm{mo}$; hazard ratio, 0.68 ; $p=0.014$ ), comparable to those shown in the SHARP trial among patients who had preserved liver function $(97 \%$ with Child-Pugh class A cirrhosis). The role of sorafenib in patients with Child-Pugh class $\mathrm{B}$ cirrhosis is still under investigation. The Global Investigation of Therapeutic Decisions in HCC and of Its Treatment with Sorafenib study (GIDEON) is an ongoing, global, prospective, and observational study undertaken to evaluate the safety of sorafenib in patients with unresectable HCC in real-life practice, including ChildPugh B patients who were excluded from clinical trials (Lencioni et al. 2014). The second interim analysis of the GIDEON study (a total of 1571 patients, $23 \%$ of which were ChildPugh B patients) has suggested that the overall 
safety profile and dosing strategy are similar across the Child-Pugh subgroups. However, patients with Child-Pugh class B cirrhosis were more likely to discontinue treatment because of adverse effects ( $38 \%$ vs. 23\%), and had worse median overall survival (5 mo vs. $10.5 \mathrm{mo}$ ), compared with the Child-Pugh class A patients (Lencioni et al. 2014). Current guidelines uniformly recommend sorafenib as a standard systemic therapy for patients with advanced HCC not amendable to resection, ablation, or transplantation but with well-preserved liver function (Child-Pugh class A) (Poon et al. 2009; EASL-EORTC 2012; NCCN 2014). Currently, there is still inadequate evidence to recommend sorafenib for patients with ChildPugh class B or C cirrhosis.

\section{Cytotoxic Chemotherapy}

Currently, there is no standard second-line chemotherapy agent for patients who fail sorafenib treatment. Chemotherapy has not been used routinely for patients with advanced HCC because, traditionally, HCC is considered to be a chemotherapy-refractory tumor (Burroughs et al. 2004), and systemic chemotherapy is usually not well tolerated by patients with significant underlying hepatic dysfunction. Nevertheless, chemotherapy may still be warranted in some individuals, particularly in those with underlying noncirrhotic liver. Among the available chemotherapeutic agents, single-agent doxorubicin has been the most studied agent for advanced HCC, with an objective response rate of $\sim 20 \%$ or less with doses of $75 \mathrm{mg} / \mathrm{m}^{2}$ (Lai et al. 1988; Burroughs et al. 2004; Yeo et al. 2005). Various combination chemotherapy regimens have been tested to improve efficacy but the results have been disappointing (Burroughs et al. 2004). In general, cytotoxic chemotherapy should be reserved for medically appropriate patients with adequate hepatic function, preferably administered within the context of a clinical trial.

\section{Immunotherapy}

Cancer cells evading immune destruction have emerged as a hallmark of cancer (Hanahan and
Weinberg 2011). HCC has been shown to be immunogenic, and immune therapeutic strategies have been introduced for HCC treatment, aiming to selectively target tumor cells by inducing or boosting the existing tumor-specific immune response (Breous and Thimme 2011). In this regard, immune-checkpoint-pathway inhibitors such as anti-cytotoxic T-lymphocyte antigen 4 (CTLA-4) antibody (ipilimumab) have been introduced for the treatment of patients with advanced melanoma with promising results (Hodi et al. 2010). Programmed death 1 (PD-1), a coinhibitory receptor molecule that is expressed by activated $\mathrm{T}$ and $\mathrm{B}$ cells, plays an important role in regulating peripheral immune tolerance (Keir et al. 2008). The interactions between PD-1 and its ligands, programmed death ligand 1 (PD-L1) (B7-H1) and PD-L2 (B7-DC), is a crucial immune checkpoint and a major mechanism of immune suppression within the tumor microenvironment (Zou and Chen 2008; Sznol and Chen 2013). Overexpression of PD-L1 has been shown to be associated with tumor aggressiveness and postoperative recurrence in HCC patients (Gao et al. 2009). Shi et al. also showed that PD-1 expression was increased in tumorinfiltrating effector $\mathrm{CD}^{+} \mathrm{T}$ cells, and this increase in PD- $1+\mathrm{CD}^{+} \mathrm{T}$ cells was predictive of disease progression and postoperative recurrence in HCC patients (Shi et al. 2011). More recently, Umemoto et al. (2014) showed expression of PD-L1 on cells of HCC correlated with the number of CD163-positive macrophages and HLA class I expression with CD3-positive cell infiltration, and combined PD-L1 low/HLA class I high expression on HCCs was prognostic for improved overall survival and recurrencefree survival. Several PD-1 antagonist antibodies, such as nivolumab (MDX-1106, BMS936558), pembrolizumab (MK-3475), and pidilizumab (CT-011), have been developed and are currently being evaluated in clinical trials in various cancers (Topalian et al. 2012; Sznol and Chen 2013). Among these anti-PD-1 antibodies, nivolumab, a fully human monoclonal immunoglobulin (Ig)G4 antibody that binds PD-1 with high affinity and blocks its interaction with both B7-H1 and B7-DC, is currently 
being investigated in a phase I study specifically designed for patients with advanced HCC with or without viral hepatitis (No. NCT01658878, ClinicalTrials.gov).

Other immunotherapeutic strategies have included identifying tumor-associated antigens (TAAs) recognized by cytotoxic T lymphocytes (CTLs) to enhance host immunity to the HCC. The TAAs that have been discovered in HCC tumors include cyclophilin B, squamous cell carcinoma antigen recognized by $\mathrm{T}$ cells (SART) 2, SART3, AFP, human telomerase reverse transcriptase (hTERT), glycopican-3 (GPC3), NYESO-1, SSX-2, and melanoma antigen gene A (MAGE-A), etc. (Mizukoshi et al. 2011; Liang et al. 2013). Adoptive immunotherapy by autologous dendritic cells pulsed with specific TAA (tumor vaccines) is an emerging clinical strategy and has been tested in early phase clinical trials in patients with HCC (Butterfield et al. 2006; Palmer et al. 2009). Palmer et al. (2009) showed that the disease-control rate (combined partial response and stable disease $\geq 3 \mathrm{mo}$ ) was $28 \%$ in 25 patients with HCC who had undergone intravenous vaccination with mature autologous dendritic cells pulsed ex vivo with a liver tumor cell line lysate (HepG2) (Palmer et al. 2009). More insights into the mechanisms underlying HCC immunology are crucial for further development of novel immune therapies (Breous and Thimme 2011).

\section{Oncolytic Virus Therapy}

Oncolytic virotherapy has emerged as a new anticancer strategy, which implicates selective replication of oncolytic viruses in cancerous tissues to lyse tumor cells (Chang et al. 2009a; Russell et al. 2012). Oncolytic viruses are designated tumor-selective, multimechanistic antitumor agents, and the commonly used virus classes include adenovirus, parvovirus, herpes simplex virus, poxvirus, paramyxovirus, reovirus, etc. (Russell et al. 2012; Moehler et al. 2014). The preferential tropism of cancer cells by oncolytic viruses is based on the characteristic impaired antiviral responses and higher permissiveness for virus replication of cancer cells (Russell et al. 2012). Moreover, oncolytic virus- es are often genetically engineered (genetic arming) to enhance therapeutic effects. The anticancer effects of oncolytic viruses are multimechanistic, ranging from direct virus-mediated cancer cell killing, pleiotropic cytotoxic immune effector mechanisms, through the specific activities of transgene-encoded proteins (Russell et al. 2012). Furthermore, by generating tumor cell lysates in situ, oncolytic viruses may overcome cellular tumor-resistance mechanisms and induce immunogenic tumor cell death resulting in the recognition of newly released tumor antigens (Moehler et al. 2014).

There are a number of oncolytic virus platforms currently in development, some of which are being tested in clinical trials for HCC patients. The oncolytic vaccinia virus pexastimogene devacirepvec (Pexa-Vec, JX-594), armed with granulocyte-macrophage colony-stimulating factor (GM-CSF)-expressing genes, is a representative lead from the targeted and armed oncolytic poxvirus class for HCC treatment (Kim et al. 2006; Kirn and Thorne 2009; Merrick et al. 2009; Parato et al. 2012). Pexa-Vec utilizes the unique characteristics of vaccinia, which allows the virus to survive in the bloodstream in the presence of neutralizing antibodies, leading to its ability to be administered both intravenously and intratumorally (Kim et al. 2006). Pexa-Vec has shown proof-of-concept mechanisms in clinical trials for cancer patients, including HCC patients (Liu et al. 2008; Park et al. 2008; Hwang et al. 2011; Kim et al. 2013). Notably, Liu et al. (2008) showed that HCC tumor tissue could serve as a source of acute HBV replication and posttreatment HBV release, and that Pexa-Vec can suppress underlying HBV replication in HCC patients. In a phase I trial, Pex-Vec administered directly into the tumor showed objective responses in three of ten evaluable patients with nonresectable HCC (Park et al. 2008). Dose-related survival of intratumoral Pex-Vec (median survival of 14.1 mo compared with 6.7 mo on the high and low dose) was shown in a randomized phase II dose-finding trial in $30 \mathrm{HCC}$ patients (90\% in advanced BCLC C stage) (Heo et al. 2013c). However, a preliminary report from a randomized phase IIb trial (TRAVERSE) in patients 
with advanced HCC who have failed sorafenib therapy showed that Pexa-Vec did not meet its primary end point of survival improvement as compared with best supportive care (Heo et al. 2013b). Sequential therapy of intratumoral Pexa-Vec followed by sorafenib was tested in a phase II trial in 25 treatment-refractory HCC patients (including 20 sorafenib refractory), with a disease-control rate of $62 \%$ with PexaVec alone compared with 59\% following initiation of sorafenib (Heo et al. 2013a). The determinants for optimal patient population for successful oncolytic virotherapy warrant further studies.

Other investigational oncolytic virus for HCC includes telomerase-specific replicationcompetent oncolytic adenovirus, telomelysin (OBP-301), which is developed by replacing the adenoviral E1A promoter with the tumor-specific telomerase reverse transcriptase (hTERT) promoter to allow efficient replication in telomerase-positive tumor cells (Kawashima et al. 2004). Notably, the frequencies of hTERT-positive hepatocytes were very low in noncancerous liver tissues but high in HCC tumors and were well-correlated with clinicopathological parameters: the average frequencies of chronic hepatitis was $0.2 \%$, liver cirrhosis $0.2 \%$, well-differentiated HCC 3.0\%, moderately differentiated HCC 28\%, and poorly differentiated HCC 95\% (Kawakami et al. 2000). Safety and tolerability of telomelysin has been tested in a phase I trial in 16 patients with solid cancers (but not including any patients with HCC). The most common adverse effects (grade 1 or grade 2) were fever, chills, fatigue, and injection site pain (Nemunaitis et al. 2010). However, the feasibility of using telomelysin for HCC treatment has been validated in a preclinical study using an orthotopic in situ HCC animal model (Huang et al. 2012), and so further early phase trials of telomelysin in HCC are being planned.

\section{Novel Targeted Therapy in Development}

Apart from being a tyrosine kinase inhibitor, sorafenib has recently been shown to be a direct enhancer of a tyrosine phosphatase, Src homology 2 domain containing tyrosine phosphatase 1
(SHP-1) (Tai et al. 2011, 2014). Sorafenib can induce apoptosis through enhancing SHP-1 activity and, thus, inhibiting p-STAT and its transcriptional functions (Tai et al. 2011). Interestingly, very recent studies have developed new compounds related to sorafenib (sorafenib derivatives) that target SHP-1-dependent $\mathrm{p}$-STAT inhibition, and these are currently being tested in preclinical models (Chen et al. 2011, 2012; Tai et al. 2011). These new derivatives may be a promising candidate for targeted cancer therapy and drug discovery in the future.

\section{TREATMENT FOR INTERMEDIATE STAGE}

\section{TACE}

Transarterial embolization (TAE) (embolic particles without chemotherapy) or TACE (chemotherapeutic drugs and embolic particles) therapy takes advantage of the characteristic HCC arterial blood supply and induces tumor necrosis by selective cannulation of the tumor-feeding hepatic arteries and infusion of vaso-occlusive particles and/or chemotherapy. A pivotal randomized study by Llovet et al. showed superior survival in unresectable HCC patients with Child-Pugh class A or B cirrhosis who underwent either TAE or TACE (doxorubicin and embolic particles), as compared with supportive care (Llovet et al. 2002). Another important randomized study by Lo et al. also showed that TACE (an emulsion of cisplatin in lipiodol and gelatin-sponge particles) produces a survival benefit in patients with unresectable HCC, compared with supportive care. A meta-analysis study has confirmed survival benefits of TAE/ TACE (Llovet and Bruix 2003). However, the outcome of TAE/TACE apparently depends on careful patient selection, and there is a wide range in the 2 -yr survival rates reported in prospective randomized trials $(24 \%-63 \%)$ as well as in retrospective series (11\%-47\%) (Sangro et al. 2011). Multiple studies have suggested predictors of poor outcome in HCC patients who received TACE, including advanced cirrhosis (Child-Pugh class C), portal vein thrombosis, tumor size, multifocality, and vessel invasion (Chan et al. 2002; Takayasu et al. 2006; Jeon 
et al. 2007; Raoul et al. 2011). Accordingly, absolute contraindications for TACE have been proposed, such as decompensated cirrhosis, severe reduced hepatic portal flow, and technical contraindications (Raoul et al. 2011; Cheng et al. 2014). The most common complication of TAE/TACE is the postembolization syndrome, which can occur in up to $80 \%$ of patients. This is characterized by fever, elevated alanine aminotransferase, and abdominal pain (Leung et al. 2001). Acute hepatic decompensation represents a severe complication of TAE/ TACE, which has reported an incidence as high as $20 \%$ (Chan et al. 2002). In a large prospective cohort study of 8510 patients with unresectable HCC who underwent TACE, the 5-yr survival rate was $26 \%$ after TACE, and the treatmentrelated deaths were $44(0.51 \%)$, including 18 $(0.21 \%)$ hepatic failures (Takayasu et al. 2006).

In recent years, a novel therapeutic approach of radioembolization has shown promise for the treatment of patients with unresectable HCC. Radioembolization, technically similar to TAE/TACE, infuses radioactive microspheres (Yttrium-90 [Y-90]) into the tumor-feeding hepatic arteries. These infused microspheres selectively implant within the tumor arterioles and so deliver in situ radiation. Multiple retrospective or noncontrolled prospective studies (levels of evidence II-2 and II-3) support the use of radioembolization, but no randomized controlled trials have been published comparing radioembolization with other locoregional versus systemic therapies versus best supportive care (Sangro et al. 2012). Recently, a cost-effectiveness analysis suggested that radioembolization costs may be justified for patients with BCLC stage $C$ disease, whereas radioembolization may not be cost effective in patients with BCLC stage A disease (Rostambeigi et al. 2014). Current indications of Y-90-radioembolization include intermediate stage patients with bulky or bilobar disease, which are considered poor candidates for TACE, and advanced patients with solitary tumors invading a segmental or lobar branch of the portal vein. Radioembolization can also be used to treat patients with progression disease after TACE or sorafenib, or be used as a downstaging procedure for patients currently unfit but potentially eligible for resection, ablation, or transplantation (Sangro et al. 2012). More recently, embolization using drugeluting beads (drug-eluting beads transarterial chemoembolization [DEB-TACE]) has been introduced. Early clinical experiences have confirmed that drug-eluting beads provide a combined ischemic and cytotoxic effect locally with low systemic toxic exposure (Lencioni et al. 2012a). A randomized (PRECISION V) study comparing DEB-TACE with conventional TACE in 212 patients with Child-Pugh A/B cirrhosis and large and/or multinodular, unresectable HCCs revealed that DEB-TACE achieved similar response and disease-control rates with significantly reduced liver toxicity and doxorubicinrelated side effects (Lammer et al. 2010). Another prospective study has also reported higher rates of tumor response and longer time to progression for DEB-TACE as compared with TACE in 84 intermediate HCC patients (Malagari et al. 2010). Further large-scale prospective trials are required to further confirm survival benefits of DEB-TACE. An important limitation of all TACE regimens is tumor recurrence, which has been shown to be contributed to by increased VEGF production and subsequent angiogenesis following TACE (Gupta et al. 2006; Wang et al. 2008). Therefore, a combination of TACE with agents with antiangiogenic properties appears to be a rational approach and has been tested in clinical trials, such as a combination of sorafenib with TACE (Pawlik et al. 2011; Zhao et al. 2013) or with DEC-TACE (Lencioni et al. 2012b). In particular, the phase II randomized double-blind placebo-controlled SPACE study evaluating sorafenib in combination with DEC-TACE has met its primary end point of improving time to progression after enrolling 307 patients (Lencioni et al. 2012b). The encouraging efficacy signal will require confirmation from ongoing phase III trials.

\section{TREATMENT FOR EARLY LIVER CANCER}

For patients with early-stage hepatocellular carcinoma, a partial hepatectomy may be curative; however, a patient's overall liver function, tumor assessment, and liver anatomy must be tak- 
en into consideration. Resection is recommended in patients who have preserved liver function, generally Child-Pugh class A (good operative risk) without portal hypertension. Liver transplantation also offers patients a potential curative treatment option in early hepatocellular carcinoma.

\section{Surgical Resection (Partial Hepatectomy)}

Surgical resection is the mainstay treatment for solitary HCCs in patients with preserved liver function. With recent advances in laparoscopic liver resection, with a reduction in operative blood loss, operation time, and length of hospital stay, the surgical outcome is comparable to open hepatectomy in a selected population (Cheung et al. 2013; Kamiyama et al. 2014). In general, eligible candidates for resection must have a surgically feasible tumor location, adequate liver reserve, and a sufficient liver remnant as assessed by clinical and biochemical measures (such as indocyanine green), or by hepatic volumetry (Hemming et al. 1992; Kubota et al. 1997). For patients with borderline liver remnant, preoperative portal vein embolization can be an adjunct to liver resection, particularly for right-sided tumors (Abdalla et al. 2001; Abulkhir et al. 2008; Palavecino et al. 2009). This procedure embolizes the portal vein that supplies the tumor-bearing liver and aims to initiate hypertrophy of the anticipated future liver remnant to allow a more extensive resection (Abdalla et al. 2001). The 5-yr survival rate can reach $40 \%-70 \%$ in patients with early HCC $(<5 \mathrm{~cm})$ and preserved liver function (Poon et al. 2002; Nathan et al. 2009). Long-term outcomes after surgery are influenced by tumorrelated factors (such as the presence and degree of vascular invasion, tumor number and size, and surgical margin status) and underlying liver function, as endorsed by the different staging systems for HCC (Nathan et al. 2009). Recurrence remains a major problem after surgical resection, and common patterns of recurrence include intrahepatic local recurrence or a new second primary lesion (Poon et al. 2002). Treatment for recurrence includes repeat hepatectomy, TAE/TACE, radiofrequency ablation, or salvage liver transplantation (Chan et al. 2013).

\section{Adjuvant Therapy after Surgical Resection}

Adjuvant therapy after HCC resection holds promising potential as it may eradicate residual cancer cells and prevent secondary liver carcinogenesis. Currently, the conclusive role of adjuvant therapy following curative resection of HCC remains to be defined (Samuel et al. 2009). Nevertheless, several adjuvant strategies have been tested in clinical trials, including systemic and intra-arterial chemotherapy, intraarterial radiolabeled lipiodol, TACE, acyclic retinoids, interferon, adoptive immunotherapy, autologous tumor vaccine, and, more recently, sorafenib (Xie et al. 2012; Furtado et al. 2014). Earlier adjuvant trials in HCC suffered from deficiencies, such as small case numbers, heterogeneous patient populations, and nonstandardized end points, resulting in a lack of consolidative evidence (Samuel et al. 2009). The recent introduction of adjuvant sorafenib in patients with HCC following curative treatment (surgical resection or local ablation) in a phase III randomized, double-blind, and placebocontrolled study (STORM) unfortunately failed to meet its primary end point: no significant differences were evident in recurrence-free survival (sorafenib vs. placebo hazard ratio [HR] $=0.94 ; 95 \%$ CI, 0.78-1.134) (Bruix 2014). For patients with hepatitis virus-associated HCC, the benefits of adjuvant antiviral therapy have been shown (Kubo et al. 2013). The rationale of adjuvant antiviral therapy is that the rate of recurrence, particularly of multicentric carcinogenesis after surgery, is affected by persistent active hepatitis and hepatic fibrosis caused by HBV or HCV (Kubo et al. 2000a,b; Wu et al. 2009). Interferon therapy may improve the outcome after curative resection for $\mathrm{HCV}$-related HCC. A meta-analysis of randomized controlled trials showed that adjuvant interferon, with an $8 \%-20 \%$ discontinued rate, significantly decreased early (within 2 yr of surgery) mortality (pooled risk ratio $[\mathrm{RR}] 0.65 ; 95 \% \mathrm{CI}$, $0.52-0.80)$ and early tumor recurrence ( $R R$ 0.86 ; 95\% CI, 0.76-0.97) after curative resec- 
tion for HCV-related HCC (Breitenstein et al. 2009). However, a recent study with long-term follow-up (median $63.8 \mathrm{mo}$ ) in $268 \mathrm{HCV}$-related HCC patients reported that adjuvant interferon did not have a significantly lower risk of disease recurrence as compared with the control group (Chen et al. 2012). The true benefit of interferon awaits confirmation from larger trials with long-term outcome.

In patients with HBV-related HCC, nucleoside/nucleotide analogs may also improve the outcome after curative resection for HBV-related HCC. A two-stage longitudinal clinical study concluded that nucleos $(\mathrm{t})$ ide analog treatment significantly reduced the risk of HCC recurrence (HR 0.48; 95\% CI, 0.32-0.70) and HCC-related deaths (HR 0.26; 95\% CI, 0.14$0.50)$ after curative treatment in its randomized trial cohort $(n=163)$ (Yin et al. 2013). A nationwide population-based study from Taiwan observed a significant association of antiviral treatment with a lower risk of HCC recurrence (6-yr cumulative incidence $46 \%$ vs. $55 \%$ ) at a relatively short median follow-up duration $(\mathrm{Wu}$ et al. 2012). It should be noted that this observational database study has limitations in results interpretation. Similarly, the benefits of adjuvant nucleos(t)ide analogs in patients with resected HBV-related HCC await confirmation in larger controlled trials with adequate follow-up.

\section{Liver Transplantation}

Liver transplantation has the advantage of correcting the underlying cirrhosis, reducing the risk of postoperative liver failure, and has been generally considered the treatment of choice for patients with early-stage HCC with moderate to severe cirrhosis. Selective criteria for liver transplantation, known as the Milan criteria, were first introduced by Mazzaferro et al. (1996) and included a single tumor $\leq 5 \mathrm{~cm}$ or no more than three multiple tumors with the largest $\leq 3 \mathrm{~cm}$ in diameter, and no evidence of macrovascular involvement or extrahepatic disease. Mazzaferro et al. (1996) showed 4-yr overall and recurrence-free survival rates of $85 \%$ and $92 \%$ in HCC patients who met the Milan crite- ria and underwent liver transplantation. Subsequent studies have proposed to expand transplantation eligibility beyond the current Milan criteria to include larger and more numerous tumors (Yao et al. 2001; Duffy et al. 2007; Herrero et al. 2008). However, it remains controversial to universally accept these expanded criteria (Mazzaferro 2007). Mazzaferro et al. showed that by defining the up-to-seven rule (HCC with seven as the sum of the size of the largest tumor in $\mathrm{cm}$ and the number of tumors), there was indeed a group of HCC patients outside the conventional Milan criteria that had a comparable outcome with those within the conventional Milan criteria. This up-to-seven criteria captured most of the alternative proposals of the expansion of conventional Milan criteria (such as the University of California, San Francisco and University of California, Los Angeles criteria) (Yao et al. 2001; Duffy et al. 2007). Regional organ availability and transplantation waiting time are important factors affecting the decision to perform transplantation, and, in this regard, living-donor liver transplantation is an alternative transplantation approach for selected patients that may increase the organ donor pool, enable transplant for borderline indications, and enable early transplantation before the tumor exceeds transplantability (Sugawara et al. 2007; Lee and Moon 2013; Hackl et al. 2014). Furthermore, because donor liver availability and median liver waiting time varies among regions and may affect the outcome of liver transplantation, it is difficult to directly compare the effectiveness of liver transplantation versus partial hepatectomy in patients with resectable HCC and Child-Pugh class A cirrhosis. Recently, a meta-analysis of nine retrospective cohorts (total of 2279 patients) reported liver transplantation in HCC patients increased the late disease-free and overall survival (at $10 \mathrm{yr}$ ), compared with liver resection, but at the expense of higher short-term mortality (Rahman et al. 2012).

\section{Locoregional Therapy}

Locoregional ablative therapy, including ethanol injection, radiofrequency ablation, and 
cryotherapy, can be the primary treatment for selected inoperable patients with HCC confined to the liver, but can also be used as a bridge to liver transplantation or as a palliative procedure to extend disease-free survival.

Radiofrequency ablation (RFA), inducing thermal destruction of HCC by coagulative necrosis, has been proven superior to percutaneous ethanol injection (PEI) as the ablative therapy of choice in the treatment of early HCC (Lin et al. 2005; Shiina et al. 2005). When compared with liver resection, RFA generally is associated with lower morbidity in patients with small HCC (Feng et al. 2014). However, efficacy of RFA versus surgical resection in the treatment of early HCC remains an ongoing issue (Cho et al. 2011; Huang et al. 2011; Feng et al. 2014). Several randomized controlled studies have shown comparable overall survival of RFA versus surgical resection in patients with small HCC (tumor size less than $4 \mathrm{~cm}$ ) (Chen et al. 2006; Feng et al. 2012). However, the subgroup analysis by Chen et al. showed higher diseasefree survival rate in the resection group when tumor size ranged from 3.1 to $5.0 \mathrm{~cm}(65 \%$ at $3 \mathrm{yr}$ vs. $45 \%$ in the RFA group) (Chen et al. 2006). Recently, a meta-analysis of 22 studies concluded that there were superior survival outcomes from surgical resection of HCCs measuring $>3 \mathrm{~cm}$ compared with RFA (Cho et al. 2011; Huang et al. 2011; Feng et al. 2014). Given the nonsuperiority of RFA over surgical resection in small HCC, its inferiority in larger tumors, and the reported $12.5 \%$ risk of needletrack tumor seeding (Llovet et al. 2001), the guidelines only recommend ablation in small tumors that are not amendable to surgical resection or transplantation (Fong and Tanabe 2014). Microwave ablation has emerged in recent years, but further prospective clinical trials are needed to better delineate the role of this approach in HCC (Martin et al. 2010).

\section{CONCLUDING REMARKS}

With advances in the understanding of the steps leading to hepatocarcinogenesis, multiple novel treatment strategies have emerged, including combination therapy of current treatment mo- dalities. Treatment of liver cancer is a multidisciplinary and multimodel treatment approach with options that are chosen generally on an individualized patient basis according to the complex interplay of tumor stage and the extent of underlying liver disease, as well as patient performance status. Future efforts on the development of better predictive, diagnostic, and prognostic biomarkers of HCC as well as molecularly targeted therapy may improve the overall survival of patients with HCC across stages.

\section{REFERENCES}

Abdalla EK, Hicks ME, Vauthey JN. 2001. Portal vein embolization: Rationale, technique and future prospects. Br J Surg 88: 165-175.

Abulkhir A, Limongelli P, Healey AJ, Damrah O, Tait P, Jackson J, Habib N, Jiao LR. 2008. Preoperative portal vein embolization for major liver resection: A meta-analysis. Ann Surg 247: 49-57.

Altekruse SF, McGlynn KA, Reichman ME. 2009. Hepatocellular carcinoma incidence, mortality, and survival trends in the United States from 1975 to 2005. J Clin Oncol 27: 1485-1491.

Altekruse SF, McGlynn KA, Dickie LA, Kleiner DE. 2012. Hepatocellular carcinoma confirmation, treatment, and survival in surveillance, epidemiology, and end results registries, 1992-2008. Hepatology 55: 476-482.

Bosetti C, Levi F, Boffetta P, Lucchini F, Negri E, La Vecchia C. 2008. Trends in mortality from hepatocellular carcinoma in Europe, 1980-2004. Hepatology 48: 137-145.

Breitenstein S, Dimitroulis D, Petrowsky H, Puhan MA, Mullhaupt B, Clavien PA. 2009. Systematic review and meta-analysis of interferon after curative treatment of hepatocellular carcinoma in patients with viral hepatitis. Br J Surg 96: 975-981.

Breous E, Thimme R. 2011. Potential of immunotherapy for hepatocellular carcinoma. J Hepatol 54: 830-834.

Bruix J, Takayama T, Mazzaferro V, Chau GY, Yang J, Kudo M, Cai J, Poon RT, Han KH, Tak WY, et al. 2014. STORM: A phase III randomized, double-blind, placebo-controlled trial of adjuvant sorafenib after resection or ablation to prevent recurrence of hepatocellular carcinoma (HCC). In 2014 Annual Meeting of the American Society of Clinical Oncology (ASCO), Abstract 4006.

Burroughs A, Hochhauser D, Meyer T. 2004. Systemic treatment and liver transplantation for hepatocellular carcinoma: Two ends of the therapeutic spectrum. Lancet Oncol 5: 409-418.

Butterfield LH, Ribas A, Dissette VB, Lee Y, Yang JQ, De la Rocha P, Duran SD, Hernandez J, Seja E, Potter DM, et al. 2006. A phase I/II trial testing immunization of hepatocellular carcinoma patients with dendritic cells pulsed with four $\alpha$-fetoprotein peptides. Clin Cancer Res 12: 2817-2825.

Chan AO, Yuen MF, Hui CK, Tso WK, Lai CL. 2002. A prospective study regarding the complications of trans- 
C.-Y. Liu et al.

catheter intraarterial lipiodol chemoembolization in patients with hepatocellular carcinoma. Cancer 94: 17471752.

Chan AC, Chan SC, Chok KS, Cheung TT, Chiu DW, Poon RT, Fan ST, Lo CM. 2013. Treatment strategy for recurrent hepatocellular carcinoma: Salvage transplantation, repeated resection, or radiofrequency ablation? Liver Transpl 19: 411-419.

Chang JF, Chen PJ, Sze DY, Reid T, Bartlett D, Kirn DH, Liu TC. 2009a. Oncolytic virotherapy for advanced liver tumours. J Cell Mol Med 13: 1238-1247.

Chang MH, You SL, Chen CJ, Liu CJ, Lee CM, Lin SM, Chu HC, Wu TC, Yang SS, Kuo HS, et al. 2009b. Decreased incidence of hepatocellular carcinoma in hepatitis B vaccinees: A 20-year follow-up study. J Natl Cancer Inst 101: $1348-1355$.

Chen MS, Li JQ, Zheng Y, Guo RP, Liang HH, Zhang YQ, Lin XJ, Lau WY. 2006. A prospective randomized trial comparing percutaneous local ablative therapy and partial hepatectomy for small hepatocellular carcinoma. Ann Surg 243: 321-328.

Chen KF, Tai WT, Huang JW, Hsu CY, Chen WL, Cheng AL, Chen PJ, Shiau CW. 2011. Sorafenib derivatives induce apoptosis through inhibition of STAT3 independent of Raf. Eur J Med Chem 46: 2845-2851.

Chen KF, Tai WT, Hsu CY, Huang JW, Liu CY, Chen PJ, Kim I, Shiau CW. 2012. Blockade of STAT3 activation by sorafenib derivatives through enhancing SHP- 1 phosphatase activity. Eur J Med Chem 55: 220-227.

Cheng AL, Kang YK, Chen Z, Tsao CJ, Qin S, Kim JS, Luo R, Feng J, Ye S, Yang TS, et al. 2009. Efficacy and safety of sorafenib in patients in the Asia-Pacific region with advanced hepatocellular carcinoma: A phase III randomised, double-blind, placebo-controlled trial. Lancet Oncol 10: 25-34.

Cheng AL, Amarapurkar D, Chao Y, Chen PJ, Geschwind JF, Goh KL, Han KH, Kudo M, Lee HC, Lee RC, et al. 2014. Re-evaluating transarterial chemoembolization for the treatment of hepatocellular carcinoma: Consensus recommendations and review by an International Expert Panel. Liver Int 34: 174-183.

Cheung TT, Poon RT, Yuen WK, Chok KS, Jenkins CR, Chan SC, Fan ST, Lo CM. 2013. Long-term survival analysis of pure laparoscopic versus open hepatectomy for hepatocellular carcinoma in patients with cirrhosis: A singlecenter experience. Ann Surg 257: 506-511.

Chevret S, Trinchet JC, Mathieu D, Rached AA, Beaugrand M, Chastang C. 1999. A new prognostic classification for predicting survival in patients with hepatocellular carcinoma. Groupe d'Etude et de Traitement du Carcinome Hepatocellulaire. J Hepatol 31: 133-141.

Cho YK, Chung JW, Kim JK, Ahn YS, Kim MY, Park YO, Kim WT, Byun JH. 2008. Comparison of 7 staging systems for patients with hepatocellular carcinoma undergoing transarterial chemoembolization. Cancer 112: 352-361.

Cho YK, Rhim H, Noh S. 2011. Radiofrequency ablation versus surgical resection as primary treatment of hepatocellular carcinoma meeting the Milan criteria: A systematic review. J Gastroenterol Hepatol 26: 1354-1360.

Cillo U, Vitale A, Grigoletto F, Farinati F, Brolese A, Zanus G, Neri D, Boccagni P, Srsen N, D'Amico F, et al. 2006.
Prospective validation of the Barcelona Clinic Liver Cancer staging system. J Hepatol 44: 723-731.

CLIP. 1998. A new prognostic system for hepatocellular carcinoma: A retrospective study of 435 patients: The Cancer of the Liver Italian Program (CLIP) investigators. Hepatology 28: 751-755.

CLIP. 2000. Prospective validation of the CLIP score: A new prognostic system for patients with cirrhosis and hepatocellular carcinoma. The Cancer of the Liver Italian Program (CLIP) Investigators. Hepatology 31: 840-845.

Duffy JP, Vardanian A, Benjamin E, Watson M, Farmer DG, Ghobrial RM, Lipshutz G, Yersiz H, Lu DS, Lassman C, et al. 2007. Liver transplantation criteria for hepatocellular carcinoma should be expanded: A 22-year experience with 467 patients at UCLA. Ann Surg 246: 502-509; discussion 509-511.

EASL-EORTC. 2012. EASL-EORTC clinical practice guidelines: Management of hepatocellular carcinoma. J Hepatol 56: 908-943.

Edge SB, Byrd DR, Compton CC, Fritz AG, Greene FL, Trotti A. 2010. AJCC cancer staging manual, 7th ed. (ed. Edge SB, et al.), p. 175. Springer, New York.

Feng K, Yan J, Li X, Xia F, Ma K, Wang S, Bie P, Dong J. 2012. A randomized controlled trial of radiofrequency ablation and surgical resection in the treatment of small hepatocellular carcinoma. J Hepatol 57: 794-802.

Feng Q, Chi Y, Liu Y, Zhang L, Liu Q. 2014. Efficacy and safety of percutaneous radiofrequency ablation versus surgical resection for small hepatocellular carcinoma: A meta-analysis of 23 studies. J Cancer Res Clin Oncol 141: $1-9$.

Ferlay J, Shin HR, Bray F, Forman D, Mathers C, Parkin DM. 2010. Estimates of worldwide burden of cancer in 2008: GLOBOCAN 2008. Int J Cancer 127: 2893-2917.

Fong ZV, Tanabe KK. 2014. The clinical management of hepatocellular carcinoma in the United States, Europe, and Asia: A comprehensive and evidence-based comparison and review. Cancer 120: 2824-2838.

Furtado R, Crawford M, Sandroussi C. 2014. Systematic review and meta-analysis of adjuvant I 131 lipiodol after excision of hepatocellular carcinoma. Ann Surg Oncol 21: 2700-2707.

Gao Q, Wang XY, Qiu SJ, Yamato I, Sho M, Nakajima Y, Zhou J, Li BZ, Shi YH, Xiao YS, et al. 2009. Overexpression of PD-L1 significantly associates with tumor aggressiveness and postoperative recurrence in human hepatocellular carcinoma. Clin Cancer Res 15: 971-979.

Guglielmi A, Ruzzenente A, Pachera S, Valdegamberi A, Sandri M, D'Onofrio M, Iacono C. 2008. Comparison of seven staging systems in cirrhotic patients with hepatocellular carcinoma in a cohort of patients who underwent radiofrequency ablation with complete response. Am J Gastroenterol 103: 597-604.

Gupta S, Kobayashi S, Phongkitkarun S, Broemeling LD, Kan Z. 2006. Effect of transcatheter hepatic arterial embolization on angiogenesis in an animal model. Invest Radiol 41: 516-521.

Hackl C, Schlitt HJ, Kirchner GI, Knoppke B, Loss M. 2014. Liver transplantation for malignancy: Current treatment strategies and future perspectives. World J Gastroenterol 20: $5331-5344$. 
Hanahan D, Weinberg RA. 2011. Hallmarks of cancer: The next generation. Cell 144: 646-674.

Hemming AW, Scudamore CH, Shackleton CR, Pudek M, Erb SR. 1992. Indocyanine green clearance as a predictor of successful hepatic resection in cirrhotic patients. Am J Surg 163: 515-518.

Heo J, Breitbach C, Cho M, Hwang TH, Kim CW, Jeon UB, Woo HY, Yoon KT, Lee JW, Burke J, et al. 2013a. Phase II trial of Pexa-Vec (pexastimogene devacirepvec; JX-594), an oncolytic and immunotherapeutic vaccinia virus, followed by sorafenib in patients with advanced hepatocellular carcinoma (HCC). J Clin Oncol 31 (Abstr 4122).

Heo J, Chao Y, Jonker DJ, Baron AD, Habersetzer F, Burke J, Breitbach C, Patt RH, Lencioni R, Homerin M, et al. 2013b. Phase IIb randomized trial of Pexa-Vec (pexastimogene devacirepvec; JX-594), a targeted oncolytic vaccinia virus, plus best supportive care (BSC) versus BSC alone in patients with advanced hepatocellular carcinoma who have failed sorafenib treatment (TRAVERSE). $J$ Clin Oncol 31.

Heo J, Reid T, Ruo L, Breitbach CJ, Rose S, Bloomston M, Cho M, Lim HY, Chung HC, Kim CW, et al. 2013c. Randomized dose-finding clinical trial of oncolytic immunotherapeutic vaccinia JX-594 in liver cancer. Nat Med 19: $329-336$.

Herrero JI, Sangro B, Pardo F, Quiroga J, Inarrairaegui M, Rotellar F, Montiel C, Alegre F, Prieto J. 2008. Liver transplantation in patients with hepatocellular carcinoma across Milan criteria. Liver Transpl 14: 272-278.

Hodi FS, O’Day SJ, McDermott DF, Weber RW, Sosman JA, Haanen JB, Gonzalez R, Robert C, Schadendorf D, Hassel JC, et al. 2010. Improved survival with ipilimumab in patients with metastatic melanoma. $N$ Engl J Med 363: 711-723.

Huang J, Hernandez-Alejandro R, Croome KP, Yan L, Wu H, Chen Z, Prasoon P, Zeng Y. 2011. Radiofrequency ablation versus surgical resection for hepatocellular carcinoma in Childs A cirrhotics-A retrospective study of 1,061 cases. J Gastrointest Surg 15: 311-320.

Huang CY, Wei CC, Chen KC, Chen HJ, Cheng AL, Chen KF. 2012. Bortezomib enhances radiation-induced apoptosis in solid tumors by inhibiting CIP2A. Cancer Lett 317: $9-15$.

Huitzil-Melendez FD, Capanu M, O'Reilly EM, Duffy A, Gansukh B, Saltz LL, Abou-Alfa GK. 2010. Advanced hepatocellular carcinoma: Which staging systems best predict prognosis? J Clin Oncol 28: 2889-2895.

Hwang TH, Moon A, Burke J, Ribas A, Stephenson J, Breitbach CJ, Daneshmand M, De Silva N, Parato K, Diallo JS, et al. 2011. A mechanistic proof-of-concept clinical trial with JX-594, a targeted multi-mechanistic oncolytic poxvirus, in patients with metastatic melanoma. Mol Ther 19: $1913-1922$.

Ikai I, Takayasu K, Omata M, Okita K, Nakanuma Y, Matsuyama Y, Makuuchi M, Kojiro M, Ichida T, Arii S, et al. 2006. A modified Japan Integrated Stage score for prognostic assessment in patients with hepatocellular carcinoma. J Gastroenterol 41: 884-892.

Ishizawa T, Hasegawa K, Aoki T, Takahashi M, Inoue Y, Sano K, Imamura H, Sugawara Y, Kokudo N, Makuuchi M. 2008. Neither multiple tumors nor portal hypertension are surgical contraindications for hepatocellular carcinoma. Gastroenterology 134: 1908-1916.

Jemal A, Center MM, DeSantis C, Ward EM. 2010. Global patterns of cancer incidence and mortality rates and trends. Cancer Epidemiol Biomarkers Prev 19: $1893-$ 1907.

Jemal A, Bray F, Center MM, Ferlay J, Ward E, Forman D. 2011. Global cancer statistics. CA Cancer J Clin 61: 69-90.

Jeon SH, Park KS, Kim YH, Shin YS, Kang MK, Jang BK, Chung WJ, Cho KB, Hwang JS. 2007. Incidence and risk factors of acute hepatic failure after transcatheter arterial chemoembolization for hepatocellular carcinoma. Korean J Gastroenterol 50: 176-182.

Kamiyama T, Tahara M, Nakanishi K, Yokoo H, Kamachi H, Kakisaka T, Tsuruga Y, Matsushita M, Todo S. 2014. Long-term outcome of laparoscopic hepatectomy in patients with hepatocellular carcinoma. Hepatogastroenter$\operatorname{olog} y$ 61: 405-409.

Kawakami Y, Kitamoto M, Nakanishi T, Yasui W, Tahara E, Nakayama J, Ishikawa F, Tahara H, Ide T, Kajiyama G. 2000. Immuno-histochemical detection of human telomerase reverse transcriptase in human liver tissues. Oncogene 19: 3888-3893.

Kawashima T, Kagawa S, Kobayashi N, Shirakiya Y, Umeoka T, Teraishi F, Taki M, Kyo S, Tanaka N, Fujiwara T. 2004. Telomerase-specific replication-selective virotherapy for human cancer. Clin Cancer Res 10: 285-292.

Keir ME, Butte MJ, Freeman GJ, Sharpe AH. 2008. PD-1 and its ligands in tolerance and immunity. Аnпu Rev Immunol 26: 677-704.

Kim JH, Oh JY, Park BH, Lee DE, Kim JS, Park HE, Roh MS, Je JE, Yoon JH, Thorne SH, et al. 2006. Systemic armed oncolytic and immunologic therapy for cancer with JX594, a targeted poxvirus expressing GM-CSF. Mol Ther 14: $361-370$.

Kim MK, Breitbach CJ, Moon A, Heo J, Lee YK, Cho M, Lee JW, Kim SG, Kang DH, Bell JC, et al. 2013. Oncolytic and immunotherapeutic vaccinia induces antibody-mediated complement-dependent cancer cell lysis in humans. Sci Transl Med 5: 185ra163.

Kirn DH, Thorne SH. 2009. Targeted and armed oncolytic poxviruses: A novel multi-mechanistic therapeutic class for cancer. Nat Rev Cancer 9: 64-71.

Kubo S, Hirohashi K, Tanaka H, Tsukamoto T, Shuto T, Ikebe T, Yamamoto T, Wakasa K, Nishiguchi S, Kuroki T, et al. 2000a. Risk factors for recurrence after resection of hepatitis C virus-related hepatocellular carcinoma. World J Surg 24: 1559-1565.

Kubo S, Hirohashi K, Tanaka H, Tsukamoto T, Shuto T, Yamamoto T, Ikebe T, Wakasa K, Nishiguchi S, Kinoshita H. 2000b. Effect of viral status on recurrence after liver resection for patients with hepatitis $B$ virus-related hepatocellular carcinoma. Cancer 88: 1016-1024.

Kubo S, Takemura S, Sakata C, Urata Y, Uenishi T. 2013. Adjuvant therapy after curative resection for hepatocellular carcinoma associated with hepatitis virus. Liver Cancer 2: 40-46.

Kubota K, Makuuchi M, Kusaka K, Kobayashi T, Miki K, Hasegawa K, Harihara Y, Takayama T. 1997. Measurement of liver volume and hepatic functional reserve as a guide to decision-making in resectional surgery for hepatic tumors. Hepatology 26: 1176-1181. 
Kudo M, Chung H, Osaki Y. 2003. Prognostic staging system for hepatocellular carcinoma (CLIP score): Its value and limitations, and a proposal for a new staging system, the Japan Integrated Staging score (JIS score). J Gastroenterol 38: $207-215$.

Kudo M, Chung H, Haji S, Osaki Y, Oka H, Seki T, Kasugai H, Sasaki Y, Matsunaga T. 2004. Validation of a new prognostic staging system for hepatocellular carcinoma: The JIS score compared with the CLIP score. Hepatology 40: 1396-1405.

Lai CL, Wu PC, Chan GC, Lok AS, Lin HJ. 1988. Doxorubicin versus no antitumor therapy in inoperable hepatocellular carcinoma. A prospective randomized trial. Cancer 62: 479-483.

Lammer J, Malagari K, Vogl T, Pilleul F, Denys A, Watkinson A, Pitton M, Sergent G, Pfammatter T, Terraz S, et al. 2010. Prospective randomized study of doxorubicineluting-bead embolization in the treatment of hepatocellular carcinoma: Results of the PRECISION V study. Cardiovasc Intervent Radiol 33: 41-52.

Lee SG, Moon DB. 2013. Living donor liver transplantation for hepatocellular carcinoma. Recent Results Cancer Res 190: $165-179$.

Lencioni R, de Baere T, Burrel M, Caridi JG, Lammer J, Malagari K, Martin RC, O'Grady E, Real MI, Vogl TJ, et al. 2012a. Transcatheter treatment of hepatocellular carcinoma with doxorubicin-loaded DC Bead (DEBDOX): Technical recommendations. Cardiovasc Intervent Radiol 35: 980-985.

Lencioni R, Llovet JM, Han G, Tak WY, Yang J, Leberre M, Niu W, Nicholson K, Meinhardt G, Bruix J. 2012b. Sorafenib or placebo in combination with transarterial chemoembolization (TACE) with doxorubicin-eluting beads (DEBDOX) for intermediate-stage hepatocellular carcinoma (HCC): Phase II, randomized, double-blind SPACE trial. J Clin Oncol 30 (Abstr 154).

Lencioni R, Kudo M, Ye SL, Bronowicki JP, Chen XP, Dagher L, Furuse J, Geschwind JF, de Guevara LL, Papandreou C, et al. 2014. GIDEON (Global Investigation of therapeutic DEcisions in hepatocellular carcinoma and Of its treatment with sorafeNib): Second interim analysis. Int J Clin Pract 68: 609-617.

Leung DA, Goin JE, Sickles C, Raskay BJ, Soulen MC. 2001. Determinants of postembolization syndrome after hepatic chemoembolization. J Vasc Interv Radiol 12: 321-326.

Leung TW, Tang AM, Zee B, Lau WY, Lai PB, Leung KL, Lau JT, Yu SC, Johnson PJ. 2002. Construction of the Chinese University Prognostic Index for hepatocellular carcinoma and comparison with the TNM staging system, the Okuda staging system, and the Cancer of the Liver Italian Program staging system: A study based on 926 patients. Cancer 94: 1760-1769.

Liang J, Ding T, Guo ZW, Yu XJ, Hu YZ, Zheng L, Xu J. 2013. Expression pattern of tumour-associated antigens in hepatocellular carcinoma: Association with immune infiltration and disease progression. Br J Cancer 109: 10311039.

Lin SM, Lin CJ, Lin CC, Hsu CW, Chen YC. 2005. Randomised controlled trial comparing percutaneous radiofrequency thermal ablation, percutaneous ethanol injection, and percutaneous acetic acid injection to treat hepatocellular carcinoma of $3 \mathrm{~cm}$ or less. Gut 54: 11511156.

Liu L, Cao Y, Chen C, Zhang X, McNabola A, Wilkie D, Wilhelm S, Lynch M, Carter C. 2006. Sorafenib blocks the RAF/MEK/ERK pathway, inhibits tumor angiogenesis, and induces tumor cell apoptosis in hepatocellular carcinoma model PLC/PRF/5. Cancer Res 66: 1185111858.

Liu TC, Hwang T, Park BH, Bell J, Kirn DH. 2008. The targeted oncolytic poxvirus JX-594 demonstrates antitumoral, antivascular, and anti-HBV activities in patients with hepatocellular carcinoma. Mol Ther 16: 1637-1642.

Llovet JM, Bruix J. 2003. Systematic review of randomized trials for unresectable hepatocellular carcinoma: Chemoembolization improves survival. Hepatology 37: 429442.

Llovet JM, Bru C, Bruix J. 1999. Prognosis of hepatocellular carcinoma: The BCLC staging classification. Semin Liver Dis 19: $329-338$.

Llovet JM, Vilana R, Bru C, Bianchi L, Salmeron JM, Boix L, Ganau S, Sala M, Pages M, Ayuso C, et al.; Barcelona Clinic Liver Cancer (BCLC) Group. 2001. Increased risk of tumor seeding after percutaneous radiofrequency ablation for single hepatocellular carcinoma. Hepatology 33: $1124-1129$.

Llovet JM, Real MI, Montana X, Planas R, Coll S, Aponte J, Ayuso C, Sala M, Muchart J, Sola R, et al. 2002. Arterial embolisation or chemoembolisation versus symptomatic treatment in patients with unresectable hepatocellular carcinoma: A randomised controlled trial. Lancet 359: 1734-1739.

Llovet JM, Schwartz M, Mazzaferro V. 2005. Resection and liver transplantation for hepatocellular carcinoma. Semin Liver Dis 25: 181-200.

Llovet JM, Ricci S, Mazzaferro V, Hilgard P, Gane E, Blanc JF, de Oliveira AC, Santoro A, Raoul JL, Forner A, et al. 2008 Sorafenib in advanced hepatocellular carcinoma. $N$ Engl $J$ Med 359: 378-390.

Lu W, Dong J, Huang Z, Guo D, Liu Y, Shi S. 2008. Comparison of four current staging systems for Chinese patients with hepatocellular carcinoma undergoing curative resection: Okuda, CLIP, TNM, and CUPI. J Gastroenterol Hepatol 23: 1874-1878.

Malagari K, Pomoni M, Kelekis A, Pomoni A, Dourakis S, Spyridopoulos T, Moschouris H, Emmanouil E, Rizos S, Kelekis D. 2010. Prospective randomized comparison of chemoembolization with doxorubicin-eluting beads and bland embolization with BeadBlock for hepatocellular carcinoma. Cardiovasc Intervent Radiol 33: 541-551.

Marrero JA, Fontana RJ, Barrat A, Askari F, Conjeevaram HS, Su GL, Lok AS. 2005. Prognosis of hepatocellular carcinoma: Comparison of 7 staging systems in an American cohort. Hepatology 41: 707-716.

Martin RC, Scoggins CR, McMasters KM. 2010. Safety and efficacy of microwave ablation of hepatic tumors: A prospective review of a 5-year experience. Ann Surg Oncol 17: 171-178.

Mazzaferro V. 2007. Results of liver transplantation: With or without Milan criteria? Liver Transpl 13: S44-S47.

Mazzaferro V, Regalia E, Doci R, Andreola S, Pulvirenti A, Bozzetti F, Montalto F, Ammatuna M, Morabito A, Gennari L. 1996. Liver transplantation for the treatment of 
small hepatocellular carcinomas in patients with cirrhosis. $N$ Engl J Med 334: 693-699.

Merrick AE, Ilett EJ, Melcher AA. 2009. JX-594, a targeted oncolytic poxvirus for the treatment of cancer. Curr Opin Investig Drugs 10: 1372-1382.

Mizukoshi E, Nakamoto Y, Arai K, Yamashita T, Sakai A, Sakai Y, Kagaya T, Yamashita T, Honda M, Kaneko S. 2011. Comparative analysis of various tumor-associated antigen-specific T-cell responses in patients with hepatocellular carcinoma. Hepatology 53: 1206-1216.

Moehler M, Goepfert K, Heinrich B, Breitbach CJ, Delic M, Galle PR, Rommelaere J. 2014. Oncolytic virotherapy as emerging immunotherapeutic modality: Potential of parvovirus H-1. Front Oncol 4: 92.

Nathan H, Schulick RD, Choti MA, Pawlik TM. 2009. Predictors of survival after resection of early hepatocellular carcinoma. Ann Surg 249: 799-805.

NCCN. 2014. NCCN clinical practice guidelines in oncology: Hepatobiliary cancers. NCCN, Fort Washington, PA.

Nemunaitis J, Tong AW, Nemunaitis M, Senzer N, Phadke AP, Bedell C, Adams N, Zhang YA, Maples PB, Chen S, et al. 2010. A phase I study of telomerase-specific replication competent oncolytic adenovirus (telomelysin) for various solid tumors. Mol Ther 18: 429-434.

Okuda K, Ohtsuki T, Obata H, Tomimatsu M, Okazaki N, Hasegawa H, Nakajima Y, Ohnishi K. 1985. Natural history of hepatocellular carcinoma and prognosis in relation to treatment. Study of 850 patients. Cancer 56: $918-$ 928.

Palavecino M, Chun YS, Madoff DC, Zorzi D, Kishi Y, Kaseb AO, Curley SA, Abdalla EK, Vauthey JN. 2009. Major hepatic resection for hepatocellular carcinoma with or without portal vein embolization: Perioperative outcome and survival. Surgery 145: 399-405.

Palmer DH, Midgley RS, Mirza N, Torr EE, Ahmed F, Steele JC, Steven NM, Kerr DJ, Young LS, Adams DH. 2009. A phase II study of adoptive immunotherapy using dendritic cells pulsed with tumor lysate in patients with hepatocellular carcinoma. Hepatology 49: 124-132.

Parato KA, Breitbach CJ, Le Boeuf F, Wang J, Storbeck C, Ilkow C, Diallo JS, Falls T, Burns J, Garcia V, et al. 2012. The oncolytic poxvirus JX-594 selectively replicates in and destroys cancer cells driven by genetic pathways commonly activated in cancers. Mol Ther 20: 749-758.

Park BH, Hwang T, Liu TC, Sze DY, Kim JS, Kwon HC, Oh SY, Han SY, Yoon JH, Hong SH, et al. 2008. Use of a targeted oncolytic poxvirus, JX-594, in patients with refractory primary or metastatic liver cancer: A phase I trial. Lancet Oncol 9: 533-542.

Parkin DM. 2006. The global health burden of infectionassociated cancers in the year 2002. Int J Cancer 118: 3030-3044.

Pawlik TM, Reyes DK, Cosgrove D, Kamel IR, Bhagat N, Geschwind JF. 2011. Phase II trial of sorafenib combined with concurrent transarterial chemoembolization with drug-eluting beads for hepatocellular carcinoma. J Clin Oncol 29: 3960-3967.

Pons F, Varela M, Llovet JM. 2005. Staging systems in hepatocellular carcinoma. HPB (Oxford) 7: 35-41.
Poon RT, Fan ST, Lo CM, Liu CL, Wong J. 2002. Long-term survival and pattern of recurrence after resection of small hepatocellular carcinoma in patients with preserved liver function: Implications for a strategy of salvage transplantation. Ann Surg 235: 373-382.

Poon D, Anderson BO, Chen LT, Tanaka K, Lau WY, Van Cutsem E, Singh H, Chow WC, Ooi LL, Chow P, et al 2009. Management of hepatocellular carcinoma in Asia: Consensus statement from the Asian Oncology Summit 2009. Lancet Oncol 10: 1111-1118.

Rahman A, Assifi MM, Pedroso FE, Maley WR, Sola JE, Lavu H, Winter JM, Yeo CJ, Koniaris LG. 2012. Is resection equivalent to transplantation for early cirrhotic patients with hepatocellular carcinoma? A meta-analysis. J Gastrointest Surg 16: 1897-1909.

Raoul JL, Sangro B, Forner A, Mazzaferro V, Piscaglia F, Bolondi L, Lencioni R. 2011. Evolving strategies for the management of intermediate-stage hepatocellular carcinoma: Available evidence and expert opinion on the use of transarterial chemoembolization. Cancer Treat Rev 37: $212-220$.

Rostambeigi N, Dekarske AS, Austin EE, Golzarian J, Cressman EN. 2014. Cost effectiveness of radioembolization compared with conventional transarterial chemoembolization for treatment of hepatocellular carcinoma. J Vasc Interv Radiol 25: 1075-1084.

Russell SJ, Peng KW, Bell JC. 2012. Oncolytic virotherapy. Nat Biotechnol 30: 658-670.

Samuel M, Chow PK, Chan Shih-Yen E, Machin D, Soo KC. 2009. Neoadjuvant and adjuvant therapy for surgical resection of hepatocellular carcinoma. Cochrane Database Syst Rev doi: 10.1002/14651858. CD001199.pub2.

Sangro B, D’Avola D, Inarrairaegui M, Prieto J. 2011. Transarterial therapies for hepatocellular carcinoma. Expert Opin Pharmacother 12: 1057-1073.

Sangro B, Inarrairaegui M, Bilbao JI. 2012. Radioembolization for hepatocellular carcinoma. J Hepatol 56: 464-473.

Shi F, Shi M, Zeng Z, Qi RZ, Liu ZW, Zhang JY, Yang YP, Tien P, Wang FS. 2011. PD-1 and PD-L1 upregulation promotes $\mathrm{CD}^{+} \mathrm{T}$-cell apoptosis and postoperative recurrence in hepatocellular carcinoma patients. Int J Cancer 128: $887-896$.

Shiina S, Teratani T, Obi S, Sato S, Tateishi R, Fujishima T, Ishikawa T, Koike Y, Yoshida H, Kawabe T, Omata M. 2005. A randomized controlled trial of radiofrequency ablation with ethanol injection for small hepatocellular carcinoma. Gastroenterology 129: 122-130.

Sugawara Y, Tamura S, Makuuchi M. 2007. Living donor liver transplantation for hepatocellular carcinoma: Tokyo University series. Dig Dis 25: 310-312.

Sznol M, Chen L. 2013. Antagonist antibodies to PD-1 and B7-H1 (PD-L1) in the treatment of advanced human cancer. Clin Cancer Res 19: 1021-1034.

Tai WT, Cheng AL, Shiau CW, Huang HP, Huang JW, Chen PJ, Chen KF. 2011. Signal transducer and activator of transcription 3 is a major kinase-independent target of sorafenib in hepatocellular carcinoma. J Hepatol 55: 1041-1048.

Tai WT, Shiau CW, Chen PJ, Chu PY, Huang HP, Liu CY, Huang JW, Chen KF. 2014. Discovery of novel Src homology region 2 domain-containing phosphatase 1 agonists 
C.-Y. Liu et al.

from sorafenib for the treatment of hepatocellular carcinoma. Hepatology 59: 190-201.

Takayasu K, Arii S, Ikai I, Omata M, Okita K, Ichida T, Matsuyama Y, Nakanuma Y, Kojiro M, Makuuchi M, et al. 2006. Prospective cohort study of transarterial chemoembolization for unresectable hepatocellular carcinoma in 8510 patients. Gastroenterology 131: 461-469.

Topalian SL, Hodi FS, Brahmer JR, Gettinger SN, Smith DC, McDermott DF, Powderly JD, Carvajal RD, Sosman JA, Atkins MB, et al. 2012. Safety, activity, and immune correlates of anti-PD-1 antibody in cancer. $N$ Engl $J$ Med 366: 2443-2454.

Torzilli G, Donadon M, Marconi M, Palmisano A, Del Fabbro D, Spinelli A, Botea F, Montorsi M. 2008. Hepatectomy for stage $\mathrm{B}$ and stage $\mathrm{C}$ hepatocellular carcinoma in the Barcelona Clinic Liver Cancer classification: Results of a prospective analysis. Arch Surg 143: 1082-1090.

Ueno S, Tanabe G, Sako K, Hiwaki T, Hokotate H, Fukukura Y, Baba Y, Imamura Y, Aikou T. 2001. Discrimination value of the new western prognostic system (CLIP score) for hepatocellular carcinoma in 662 Japanese patients. Cancer of the Liver Italian Program. Hepatology 34: 529-534.

Umemoto Y, Okano S, Matsumoto Y, Nakagawara H, Matono R, Yoshiya S, Yamashita YI, Yoshizumi T, Ikegami T, Soejima Y, et al. 2014. Prognostic impact of programmed cell death 1 ligand 1 expression in human leukocyte antigen class I-positive hepatocellular carcinoma after curative hepatectomy. J Gastroenterol.

Vauthey JN, Ribero D, Abdalla EK, Jonas S, Bharat A, Schumacher G, Lerut J, Chapman WC, Hemming AW, Neuhaus P. 2007. Outcomes of liver transplantation in 490 patients with hepatocellular carcinoma: Validation of a uniform staging after surgical treatment. J Am Coll Surg 204: 1016-1027; discussion 1027-1028.

Vauthey JN, Dixon E, Abdalla EK, Helton WS, Pawlik TM, Taouli B, Brouquet A, Adams RB; American HepatoPancreato-Biliary Association; Society of Surgical Oncology; Society for Surgery of the Alimentary Tract. 2010. Pretreatment assessment of hepatocellular carcinoma: Expert consensus statement. HPB (Oxford) 12: 289-299.

Verslype C, Van Cutsem E, Dicato M, Arber N, Berlin JD, Cunningham D, De Gramont A, Diaz-Rubio E, Ducreux M, Gruenberger T, et al. 2009. The management of hepatocellular carcinoma. Current expert opinion and recommendations derived from the 10th World Congress on Gastrointestinal Cancer, Barcelona, 2008. Ann Oncol 20: viil-vii6.
Vitale A, Morales RR, Zanus G, Farinati F, Burra P, Angeli P, Frigo AC, Del Poggio P, Rapaccini G, Di Nolfo MA, et al. 2011. Barcelona Clinic Liver Cancer staging and transplant survival benefit for patients with hepatocellular carcinoma: A multicentre, cohort study. Lancet Oncol 12: 654-662.

Wang B, Xu H, Gao ZQ, Ning HF, Sun YQ, Cao GW. 2008. Increased expression of vascular endothelial growth factor in hepatocellular carcinoma after transcatheter arterial chemoembolization. Acta Radiol 49: 523-529.

Wu JC, Huang YH, Chau GY, Su CW, Lai CR, Lee PC, Huo TI, Sheen IJ, Lee SD, Lui WY. 2009. Risk factors for early and late recurrence in hepatitis B-related hepatocellular carcinoma. J Hepatol 51: 890-897.

Wu CY, Chen YJ, Ho HJ, Hsu YC, Kuo KN, Wu MS, Lin JT. 2012. Association between nucleoside analogues and risk of hepatitis B virus-related hepatocellular carcinoma recurrence following liver resection. JAMA 308: 19061914.

Xie F, Zhang X, Li H, Zheng T, Xu F, Shen R, Yan L, Yang J, He J. 2012. Adoptive immunotherapy in postoperative hepatocellular carcinoma: A systemic review. PLoS ONE 7: e42879.

Yao FY, Ferrell L, Bass NM, Watson JJ, Bacchetti P, Venook A, Ascher NL, Roberts JP. 2001. Liver transplantation for hepatocellular carcinoma: Expansion of the tumor size limits does not adversely impact survival. Hepatology 33: 1394-1403.

Yeo W, Mok TS, Zee B, Leung TW, Lai PB, Lau WY, Koh J, Mo FK, Yu SC, Chan AT, et al. 2005. A randomized phase III study of doxorubicin versus cisplatin/interferon $\alpha$ $2 \mathrm{~b} /$ doxorubicin/fluorouracil (PIAF) combination chemotherapy for unresectable hepatocellular carcinoma. $J$ Natl Cancer Inst 97: 1532-1538.

Yin J, Li N, Han Y, Xue J, Deng Y, Shi J, Guo W, Zhang H, Wang H, Cheng S, Cao G. 2013. Effect of antiviral treatment with nucleotide/nucleoside analogs on postoperative prognosis of hepatitis B virus-related hepatocellular carcinoma: A two-stage longitudinal clinical study. J Clin Oncol 31: 3647-3655.

Zhao Y, Wang WJ, Guan S, Li HL, Xu RC, Wu JB, Liu JS, Li HP, Bai W, Yin ZX, et al. 2013. Sorafenib combined with transarterial chemoembolization for the treatment of advanced hepatocellular carcinoma: A large-scale multicenter study of 222 patients. Ann Oncol 24: 1786-1792.

Zou W, Chen L. 2008. Inhibitory B7-family molecules in the tumour microenvironment. Nat Rev Immunol 8: 467477. 


\section{$\&_{\mathrm{CSH}}^{\infty} \&$ Cold Spring Harbor

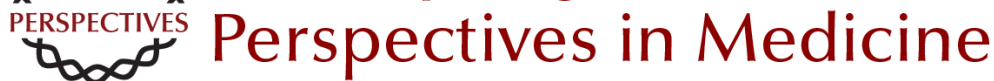

\section{Treatment of Liver Cancer}

Chun-Yu Liu, Kuen-Feng Chen and Pei-Jer Chen

Cold Spring Harb Perspect Med 2015; doi: 10.1101/cshperspect.a021535 originally published online July 17,2015

Subject Collection The Hepatitis B and Delta Viruses

Hepatitis B Virus X and Regulation of Viral Gene Expression

Betty L. Slagle and Michael J. Bouchard

The Woodchuck, a Nonprimate Model for Immunopathogenesis and Therapeutic Immunomodulation in Chronic Hepatitis B Virus Infection

Michael Roggendorf, Anna D. Kosinska, Jia Liu, et al.

Mouse Models of Hepatitis B Virus Pathogenesis Matteo lannacone and Luca G. Guidotti

Therapy of Delta Hepatitis Cihan Yurdaydin and Ramazan Idilman

Immune Response in Hepatitis B Virus Infection Anthony Tan, Sarene Koh and Antonio Bertoletti

Hepatitis D Virus: Introduction and Epidemiology Mario Rizzetto

Management of Chronic Hepatitis B in Patients from Special Populations

Ching-Lung Lai and Man-Fung Yuen

Hepatitis B Virus Genotypes and Variants Chih-Lin Lin and Jia-Horng Kao
Origins and Evolution of Hepatitis B Virus and Hepatitis D Virus

Margaret Littlejohn, Stephen Locarnini and Lilly Yuen

Assembly and Release of Hepatitis B Virus Lisa Selzer and Adam Zlotnick

Hepatitis D Virus Replication John M. Taylor

Treatment of Liver Cancer Chun-Yu Liu, Kuen-Feng Chen and Pei-Jer Chen

Hepatitis B Virus and Hepatitis D Virus Entry, Species Specificity, and Tissue Tropism Koichi Watashi and Takaji Wakita

Hepadnavirus Genome Replication and

Persistence Jianming Hu and Christoph Seeger

The Chimpanzee Model for Hepatitis B Virus Infection

Stefan F. Wieland

Hepatitis B Virus Epidemiology

Jennifer H. MacLachlan and Benjamin C. Cowie

For additional articles in this collection, see http://perspectivesinmedicine.cshlp.org/cgi/collection/ 